\title{
O Processo Sucessório em uma Instituição do Terceiro Setor - BEA - Beneficência Evangélica Aliança
}

\section{The Succession Process in an institution of the Third Sector - BEA - Beneficência Evangélica Aliança}

\author{
Clarice Mara Sousa e Silva \\ Mestranda em Administração pela Universidade Federal de Uberlândia, Brasil. \\ claricemara@hotmail.com \\ http://lattes.cnpq.br/5792426714464546
}

Edileusa Godói de Sousa

Doutora em Administração pela Universidade de São Paulo (USP). Professora Adjunta na Faculdade de Gestão e Negócios da Universidade Federal de Uberlândia, Brasil.

edileusagodoi@uol.com.br

http://lattes.cnpq.br/6843739809628564

Resumo: Este caso busca discutir o processo sucessório na BEA - Beneficência Evangélica Aliança, uma instituição do Terceiro Setor. O caso oferece oportunidades de familiarização com o modelo tridimensional para a análise do processo sucessório em empreendimentos sociais proposto por Godói-deSousa (2010). A história da BEA é relatada a partir da ótica de Rosa, uma empreendedora social, que mostra dilemas e perplexidades na reinvenção e gestão de uma instituição no resgate de crianças vítimas de violência. As três perspectivas geradoras de iniciativa de criação de uma instituição do Terceiro Setor: Indivíduo, Organização e Ambiente, estão presentes no caso.

Palavras-chave: Terceiro Setor, Sucessão, Gestão de Pessoas.

Abstract: This case discusses the succession process in BEA - Beneficência Evangélica Aliança, one of the Third Sector institutions. The case offers familiarization opportunities with the three-dimensional model for analyzing the succession process in social enterprises proposed by Godói-de-Sousa (2010). The history of the BEA is reported from the optics of Rosa, a social entrepreneur who shows dilemmas and perplexities in the reinvention and management of an institution in the rescue of child victims of violence. The three perspectives of generating prospects of creating an initiative of a third institution Sector: Individual, Organization and Environment, are present in the case.

Key Words: Third Sector, Succession, People Management

Texto completo em português: http://www.apgs.ufv.br Full text in Portuguese: http://www.apgs.ufv.br

\section{A Ovelha Perdida}

"Qual de vocês que, possuindo cem ovelhas, e perdendo uma, não deixa as noventa e nove no campo e vai atrás da ovelha perdida, até encontrá-la?” Jesus Cristo. (Lucas 15:4) - Trecho da parábola da Ovelha Perdida

Jeferson e seu irmão José Carlos chegavam ao Abrigo João da Luz. Ele tinha apenas seis anos de idade. Nunca tinha ido à escola, nem tinha brinquedos. Sua mãe o abandonara, e ele nem se lembrava de quando isto havia acontecido. O que era aquilo tudo? Onde ele estava? Nunca havia Ihe passado pela cabecinha o que era um abrigo. Seu irmão tinha 14 anos e já praticava furtos na cidade para se manter. Aprendera com o pai.

O pai de Jeferson ensinava os filhos a roubarem as casas do bairro. Aliás, não somente isso: ele maltratava, humilhava e abusava sexualmente dessas crianças quase todos os dias. Agora alguma coisa tinha acontecido e ele não sabia bem o quê. Era uma noite fria do ano 2000, ele e seu irmão chegaram a um lugar onde tinham uma cama e um teto, e encontraram outras crianças estranhas. Ele não sabia onde. Ele não sabia o porquê. Jeferson só sabia de uma coisa: ele tinha medo, muito medo.

\section{O Pastor Perdido}

"Quem me chamou / Quem vai querer voltar pro ninho Redescobrir seu lugar/Pra retornar e enfrentar o dia a dia / Reaprender a sonhar"

Trecho da letra: Brincar de Viver, de Guilherme Arantes

A história da Beneficência Evangélica Aliança (BEA) começa bem antes de 2002. Fundada em 1959 e com uma história de caridade na cidade, não parecia ser isto que Rosa via quando assumiu o cargo de presidente em 2002. Participante ativa de trabalhos voluntários na cidade fora convidada pelo conselho da igreja a assumir a BEA e ficou tomada de felicidade: "agora, poderei realizar mais coisas boas pela minha cidade!". Mas quando os componentes de sua equipe tomaram conhecimento da real situação, ficaram impressionados:

"Nós tínhamos lá uma creche com apenas 12 crianças e duas funcionárias, com toda a situação irregular, trabalhista, financeira, de pagamentos, e nós estudamos uma possibilidade de resolver aquele problema! Fomos à Delegacia de Ensino, e não tínhamos relatórios para apresentar. Pedimos a suspensão do trabalho naquele ano e remanejamos essas crianças através da Secretaria de Educação para outras creches do município, para que não fosse negligenciado o direito delas de educação. $E$ ficamos durante uns seis meses mais ou menos pensando 
em como faríamos pra resolver o problema financeiro. Decidimos buscar recursos financeiros junto ao Conselho da igreja, e pedimos que eles investissem financeiramente para que pudéssemos quitar a dívida dos funcionários".

Depois desta triste surpresa, Rosa e a sua equipe ficaram perdidos, e se perguntando o que iriam fazer!

"Começamos a buscar um novo foco para a instituição. Entendíamos a importância da BEA dentro de Aliança, uma instituição que já tinha quarenta e tantos anos de atuação dentro do município. Um amor, um legado que nós não podíamos desprezar, e jogar fora! $E$ nós buscamos qual seria a nova possibilidade da instituição, colaborar num processo social, numa necessidade do município! Percebemos que Aliança não precisava naquele momento de creche! As crianças estavam sendo bem atendidas. Com a reorganização da legislação, tudo o que estava acontecendo com as creches e a orientação da parte educacional deixavam de ser Serviço Social. A BEA era uma instituição de Assistência Social às pessoas necessitadas. Não tinha foco de educação, mas foco social. Então, fomos à Prefeitura, na Secretaria de Trabalho e Ação Social buscando respostas para isso, a fim de apresentarmos a instituição: queremos trabalhar! Como podemos colaborar? Buscamos o Ministério Público da cidade, e também o prefeito. Buscamos este encontro, e apresentamos a instituição! A instituição se reorganizava e queríamos atuar com trabalho social."

Nesta época, a creche foi fechada. A equipe de Rosa queria fazer algum trabalho com excelência, e a creche não estava atendendo a este objetivo. Mas membros da igreja atacaram a decisão de Rosa de fechar a creche, e julgaram a decisão como errada. Rosa e sua equipe ficaram muito tristes. Afinal de contas, há quantos anos a creche existia!

Mesmo sem o apoio de muitos membros da igreja, Rosa e sua equipe continuaram a investigar as necessidades do município, tentando descobrir em que a BEA poderia ser útil na cidade.

\section{O Pastor encontra a sua Ovelha}

"E quando a encontra, coloca-a alegremente nos ombros e vai para casa” Jesus Cristo. (Lucas 15:5 e 6) - Trecho da Parábola da Ovelha Perdida

Em 2003, Rosa e sua equipe, com suas conversas no Ministério Público e Conselho Tutelar, ficaram sabendo do Abrigo João da Luz, que estava abandonado. Souberam ainda que havia um remanescente: três meninos. José Carlos, agora com 16 anos, Rafael, com 12 anos, e Jeferson. Rosa e sua equipe foram visitar os meninos. Pôs os olhos em Jeferson. Ele já tinha oito anos. Para ela, aquele menino nascia naquele momento. Para ele, o que era a vida? Ele nem sabia direito a sua idade.

Ela correu ao Ministério Público, e pediu à Promotora: "Nós podemos assumir aquelas crianças! Por favor, nos ajude!" Estava claro para Rosa e sua que eles precisavam de um conhecimento técnico e habilidades que não tinham naquele momento. Mas era preciso tomar uma decisão importante, e o que movia a equipe era a convicção de que aquelas crianças precisavam de ajuda. Eles estavam inconformados.

Os jovens estavam abandonados. Praticavam furtos, prostituíam-se, drogavam-se. Dois membros da equipe de Rosa começaram a dormir no mesmo local com os meninos, para criar vínculos com eles. Só havia uma palavra no coração de Rosa e de sua equipe para aqueles meninos: compaixão. E eles iriam lutar pelos direitos daqueles meninos a partir de agora.

"Com esses três meninos sendo a motivação do projeto, começamos a lutar pelos seus direitos! E a promotoria, a princípio, também sensibilizada com o histórico de todos eles, buscou a garantia do direito daqueles adolescentes, começou a lutar no município. Nós começamos a trazer para o município o entendimento da responsabilidade do governo municipal de cuidar dessas crianças, independente de onde elas estivessem.

Foi aí que trouxemos a proposta das Casas-lares. Aí, escrevemos o projeto Casa-lar, com essa fomentação de busca de recursos, de entendimento, de discussão do Ministério Público, da Assistência Social. Não tínhamos esse conhecimento técnico. Eu lia tudo que podia. Buscando conhecimento, como é que acontecia fora. Já existiam Casas-lares, ONGs, mas de outra forma. Abrigamentos com grandes números de crianças, mas a Casa-lar trazia uma proposta de acompanhamento individualizado. "

Com o projeto Casa-lar escrito, o Ministério Público de Aliança propôs então a organização da situação do abrigamento na cidade. Ele exigiu que a Prefeitura alugasse uma casa para a BEA. Jeferson, seu irmão José Carlos, e Rafael foram os primeiros abrigados da BEA.

Rosa e sua equipe comemoraram. Resgataram os três meninos. Haviam começado o primeiro trabalho de Casas-lares da cidade, em 2006.

O Ministério Público e o Conselho Tutelar puderam contar com uma parceria para encaminhar crianças e adolescentes em situações de excepcionalidade. Estas crianças não precisavam mais ficar expostas à violência recorrente de suas famílias. Todos estavam muito satisfeitos, e foram dormir aquela noite com uma sensação de dever cumprido.

\section{Agora é brincar de viver}

"Você verá que é mesmo assim / Que a história não tem fim Continua sempre que você responde "sim"

À sua imaginação / $\grave{A}$ arte de sorrir cada vez que o mundo diz "não"

Trecho da letra: Brincar de Viver, de Guilherme Arantes

Parecia coisa simples a Prefeitura alugar uma casa para BEA e Rosa e sua equipe receberem Jeferson e as demais crianças na casa. Não foi. Rosa e sua equipe passaram por muitos problemas. Buscar conhecimentos e habilidades técnicas era preponderante para o sucesso da Casa-lar.

"Quando assumi a BEA em 2002, não tínhamos documentação nenhuma em dia. Aos poucos, tivemos que regularizar tudo. Relatórios contábeis. Em 2002, organizamos o estatuto e ele foi registrado em cartório. Criamos o Regimento Interno. Sem isto não conseguiríamos nada. No Estatuto criamos a figura dos 40 associados: 20 efetivos e 20 suplentes. Fizemos a primeira eleição em 2003. Aí é que eu fui eleita de verdade. Porque até então eu tinha sido só indicada pelo conselho da Igreja, a instituidora da BEA. Na época, criamos também o Conselho Fiscal, formado por três pessoas, e três suplentes. Então, ficou assim na BEA: o presidente, o vice-presidente, o tesoureiro, o segundotesoureiro, o secretário, o segundo-secretário.

Ainda bem que eu sempre tive o Manoel ao meu lado. Ele é contador. Sempre esteve na Diretoria da BEA como 
secretário. Mas ele é muito mais do que isto. É um aliado, um parceiro. Durante todos os anos de BEA, tivemos que ir criando nossos formulários, nossos processos. Não tínhamos nada. À medida que precisávamos, ou que éramos demandados, íamos criando, ou buscando ajuda. Nunca foi fácil!"

As crianças começavam a chegar, com seus dramas, suas histórias, suas dores. Como lidar com isto? Rosa estava tentando conciliar o trabalho de 24 horas da Casa-lar com as suas atividades rotineiras. Não estava dando certo. As crianças chegavam a todo o momento. Especialmente à noite, quando seus dramas se tornavam piores com as brigas de seus pais, e a intensificação das denúncias.

"Eu tentava conciliar. Mas eu precisava estar disposta a todo o momento, criança com febre, com dor, menino doente, menino dando piti, mãe-social querendo abandonar o cargo, desavença entre os próprios profissionais. Muitos dos próprios profissionais que vem, às vezes viveram a mesma situação lá na infância e aquilo aflora. Tivemos muitos casos assim: mães-sociais que foram abusadas sexualmente quando crianças. Quando elas começam a receber as crianças com a mesma dor, elas simplesmente travam! O que fazer nesta hora? Este profissional é super importante pra nós, e a dor dele é a dor da criança! Precisávamos cuidar delas, porque a vivência delas poderia nos ajudar. Não podíamos desprezar uma mãe-social como ser humano e como profissional!"

Em situações como esta, Rosa e sua equipe se perguntavam: o que poderíamos fazer para contratar e reter as pessoas certas em nossa equipe?

Além dos problemas ligados à gestão de pessoas, dificuldades financeiras afloravam. O comprometimento financeiro da prefeitura não estava a contento. Ela simplesmente não depositava o dinheiro que havia se comprometido. Como alimentar as crianças e pagar as contas? Os problemas se assoberbavam.

"Foi feito um Termo de Ajuste de Conduta. O Ministério Público fez um documento onde havia a obrigatoriedade do município em repassar recursos financeiros a Casa-lar, e o responsável legal é o prefeito. Houve momentos, em dois governos diferentes, em que o município só se posicionou quando foi dada uma ordem de prisão do prefeito!

Ficamos sem dinheiro em diversas situacões. Nós temos uma planilha financeira feita pelo contador, onde a folha salarial tem todas as previsões do custo daquele funcionário durante 0 ano. Férias, 13ํㅡ, período gestacional. A maioria dos nossos funcionários é mulher. Nós tínhamos um fundo de caixa para o cumprimento disto. Paga-se o funcionário mas fica-se resguardado o fundo de garantia, o 13을 as férias, etc. Chegou um momento em que nós tivemos que abrir, pegar deste fundo e usar. Começamos a viver de doações. O repasse da prefeitura é a única fonte de recursos regulares da $B E A$, e eles ficavam três, quatro meses sem repassar recursos. E a gente ficava tentando negociar, tentando entrar com procurador do município, fazendo uma articulação amigável. Quando isso não acontecia, então a gente buscava junto à justiça a atuação deles para que a coisa acontecesse."

\section{Pastor e Ovelha caminham juntos}

"E eu desejo amar todos que eu cruzar pelo meu caminho

Como sou feliz, eu quero ver feliz / Quem andar comigo, vem"

Trecho da letra: Brincar de Viver, de Guilherme Arantes

"Tia Rosa, por que minha mãe me abandonou?"
"Jeferson, tem muitas coisas que a gente não entende, mas a gente não pode segurar estas coisas no coração com amargura. Sua mãe teve as razões dela. Não guarde amargura, guarde amor. Tente viver sua vida. É possível ser feliz, apesar de tudo o que você passou! "

Continuar a viver apesar dos problemas e superá-los não era só um desafio para as crianças, era o desafio da BEA. Rosa tinha terminado sua primeira gestão 2003-2005 e a segunda gestão (2006-2008) caminhava para o fim. Fora eleita novamente, e tinham muitos sonhos ainda não concretizados. O grande desafio deste momento estava ligado às competências técnicas da equipe. Como levantar fundos? Como escrever projetos? Como regularizar documentações? Como adquirir e compartilhar conhecimento?

"Conseguimos um terreno doado pela prefeitura. Tivemos muitas dificuldades para acertar tudo! Ganhamos uma verba parlamentar para construir a cobertura de uma quadra. Precisávamos escrever um projeto. Aprendemos tudo juntos, pesquisando, perguntando, indo atrás. Tivemos a ideia dos jantares solidários. Vendemos cotas de mesas para conseguir construir os muros do terreno que ganhamos. E automaticamente já construímos também a cobertura da quadra. Ficou lá aquele terreno com a cobertura da quadra. E nisso nós ficamos sabendo que 0 instituto $A B N$ destinava recursos para projetos, $e$ que naquele ano o projeto era para construção de até 70 mil reais. Eu não sabia escrever projeto dentro das normas que eles exigiam no formulário. Nós pedimos ajuda de uma pessoa da igreja, e juntas nós fomos escrevendo este projeto."

No final de 2008, era preciso fazer uma nova eleição, e Rosa precisava sair da diretoria, conforme rezava o Estatuto, mesmo com tantos projetos em andamento. Como poderiam realizar esta transição?

"No final de 2008, concorremos com mais de 190 projetos do $A B N$ a nível nacional, e nós ficamos em 9 ㅇ lugar. Então, recebemos o recurso para construção da primeira casa. Assim que nós conseguimos construir primeira casa, transferimos os meninos pra lá.

Conseguir alguém para tocar tanta coisa junta era muito difícil, mas éramos uma equipe. Aí, fizemos um acordo. A Cora topou ser a presidente da BEA, desde que eu ficasse como Coordenadora. Criamos este cargo pra mim, remunerado. Aí, eu poderia continuar a tocar todos os projetos da BEA com toda a equipe. O Manoel também fez o acordo, e permaneceu na diretoria."

Então, na gestão 2009-2011, Cora assumiu a presidência da BEA. Os projetos, no geral, estavam a pleno vapor. Rosa estava em paz com a transição.

"Fiquei em paz com esta transição. Cora tinha o principal para assumir a presidência da BEA: o amor pelas crianças. Nós fomos aprendendo juntas. Além disto, o marido dela, o Gomes, sabia tudo de construção. Eu não sabia nada. Eu nunca construí um barraco. Tivemos que ir atrás destas pessoas que sabiam de construção. Ele colaborou muito nesta fase. Trouxemos também o Jeremias para nos ajudar com a parte de construção. Não sabíamos nada daquilo!

Como eu não sabia nada de construção, fiquei mais com a parte de documentação. Nós precisávamos ainda regularizar muita coisa."

A segunda casa veio por intermédio do Ministério Público do Trabalho, com recursos de multa de uma empresa com excesso de hora-extra do município. Era preciso ser aplicada no município com projetos com crianças e adolescentes. Então eles entraram em contato com o Ministério Público, que prontamente indicaram a BEA. Todos ficaram em êxtase. 
"A correria nesta época era muita. Buscávamos documentação da instituição, porque pra concorrer com projetos como o do ABN precisávamos da Utilidade Pública Federal, e a instituição não tinha. Precisávamos de relatórios financeiros, sociais, contábeis de três anos seguidos. E a BEA seria inscrita dentro dos conselhos. Então nós nos fizemos representar dentro dos conselhos. Aprendemos tudo andando olhando edital, nota de rodapé. Manoel foi parceiro $100 \%$, ele nunca foi só o contador, o secretário. Ele sempre foi o paizão, o pai do projeto. Porque quando a gente tinha problema na casa, o Manoel ia pra lá, de noite, fazia roda de conversa, discutia, conversava com os meninos, tinha autoridade de pai dos meninos. Tivemos vários casos de adolescentes usuários de drogas infratores, e precisávamos lidar com isto. Ele sempre nos apoiou."

\section{A Ovelha Torna-se Pastor}

"Ao chegar[em casa], reúne seus amigos e vizinhos e diz:

'Alegrem-se comigo, pois encontrei minha ovelha perdida'.

Jesus Cristo. (Lucas 15: 6) - Trecho da Parábola da Ovelha

\section{Perdida}

A gestão de Cora está chegando ao fim. Uma nova eleição precisa ser feita. Rosa continua na Coordenação do Projeto. São jantares solidários, projetos de construção, crianças que chegam, crianças que se vão. Manoel continua inabalável na diretoria e sendo uma referência para as crianças. Mirna, uma conselheira comprometida, responsável, com grande amor pelas crianças e pelo projeto, empresária na cidade, assume a presidência da BEA na gestão 2012-2014.

No começo do ano de 2012, o pai de Rosa adoece gravemente. Sua irmã avisa que ele está internado. O diagnóstico médico vem com uma orientação: ele precisa de cuidados especiais contínuos. Rosa precisa tomar uma decisão: cuidar de seu pai ou permanecer na BEA.

"De todas as difíceis tarefas, a mais difícil é a do acolhimento das crianças. Porque é comum quando chega uma criança de uma família que brigou por causa de bebida, ou por uma situação financeira insustentável. Mas quando chega uma criança que foi violentada sexualmente pelo pai ou pelo padrasto, que é uma situação muito séria, você percebe que todo esforço se faz por aquela criança ou por aquele adolescente não é suficiente, e eles não conseguem superar muitas coisas, e talvez nunca mais cheguem a ser as mesmas pessoas. Quando chegam crianças com esse histórico, mexe muito com a gente, ainda que a gente não tenha vivenciado isso.

Chegou certa vez uma criança com 11 meses que era abusada sexualmente pelo próprio pai, e o bebê já veio com doença sexualmente transmissível. Outra vez, meninos chegaram contando histórias em que isso era feito coletivamente dentro da casa com a permissão da mãe. Aquilo machuca demais. A gente se sente impotente porque não consegue alcançar o coração deste menino para liberar o perdão ou para entender que ainda que ele esteja vivendo tudo aquilo, é possível que ele seja feliz, é possível que ele sonhe, é possível que ele busque uma nova forma de viver. Muitos deles se fecham. É um trabalho árduo! E é no dia-a-dia que a gente percebe que ainda tem muito ainda pra fazer, porque os casos vão aumentando. Quem teria o perfil para assumir a coordenação da Casa-lar? Como eu posso abandonar tudo agora?"

Rosa está certa de que decisões acerca de mudanças na liderança não envolvem apenas aspectos ligados ao conhecimento técnico. Existem mais elementos envolvidos, e encontrar pessoas com o perfil desejado de liderança da instituição é um grande desafio. Em março de 2012, Rosa decide deixar voluntariamente a coordenação da BEA para cuidar da saúde de seu pai. E agora? Quem assumiria a coordenação da BEA?

"Na realidade, eu entendo que de alguma forma eu tenho alguma participação lá, e isso alegra o meu coração. É como um filho que às vezes você precisa se afastar, mas ainda continua sendo seu filho. Então eu me sinto mãe desse projeto, eu tenho amor por ele. Eu não meço sacrifícios para atender e acompanhar a própria diretoria na orientação dos trabalhos. Principalmente na parte jurídica, na busca de captação de recursos para continuidade do projeto. É uma das responsabilidades que eu tenho com o projeto. Anualmente a gente faz essas ações, esses eventos, busca parceria, busca recursos através do Fundo da Infância, com empresários. Esse envolvimento eu tenho cotidianamente.

Eu faço isso de coração, voluntariamente. Eu trago os meninos aos domingos pra passar o dia comigo. A história da Casa-lar está em mim. $E$ eu não quero que isso se apague. Acho que Aliança hoje não tem mais condições de existir, de continuar sem um projeto dessa grandeza. Um projeto de amor, de resgate de vidas, e que o nosso saldo positivo é a felicidade dessas crianças."

O mandato de Mirna está se aproximando do fim. Quem será a nova presidente da BEA? Mirna será reeleita? Algumas pessoas começam a inquirir Rosa, se esta teria interesse em voltar para a BEA. Será que Rosa deveria voltar? Como estaria o seu coração?

"Acho que a BEA está bem melhor hoje do que quando começou, com certeza. Quero acreditar que sim. A Cora, a Mirna e toda a equipe ama o projeto de verdade e luta por ele. Eu sinto falta do projeto. Mas não sei se tenho vontade de voltar a trabalhar como antes, porque foram anos de doação total, de muito esforço! Eu acredito que hoje $60 \%$ do que foi projetado de construção já aconteceu. No atendimento das crianças, eu entendo que pode melhorar ainda, mas nós já fizemos muito. Foram mais de 350 crianças e adolescente que passaram por ali. "

Após 12 anos passados, Rosa está repensando suas qualidades e fraquezas diante do desafio de uma presidência como a da BEA. Existe alguém no mundo plenamente competente para este desafio?

"Pra assumir a presidência de uma instituição como a $B E A$, não tem jeito: em primeiro lugar é preciso ter o amor pelas vidas. Nossa área de atuação: vidas. $E$ eu acho que tem que gostar de fazer essa gestão com pessoas, porque é uma empresa com 20 funcionários. Então tem que saber fazer funcionar isto aí. E ter essa visão administrativa. Porque com a própria diretoria, é importante isso, planejamento das ações.

Ah!!! A busca de novos conhecimentos! Porque toda hora é uma coisa de louco, principalmente na parte jurídica! Aprendemos a deixar tudo devidamente registrado!"

Após a saída de Rosa da coordenação da BEA, em março de 2012, assume seu lugar Carolina, profissional que trabalhava na área de contabilidade da Ação Social da Prefeitura de Aliança. Com os anos de contato e envolvimento com o projeto, Carolina recebeu o convite como um grande desafio.

Em 2014, Jeferson fez 18 anos e foi oficialmente desligado da Casa-lar. A mãe e o pai dele perderam sua guarda definitiva e de seus irmãos também. Ele passou os últimos 10 anos na Casa-lar. Estudou. Foi para São Paulo aprender a adestrar cães. Faz curso de inglês. Está trabalhando e terminando o 2o grau. Junta todo o dinheiro que ganha numa poupança. 
"Tia Rosa, vou montar um Pet Shop pra mim. Vou ser um empresário! "

Jeferson alugou uma casa perto da BEA e vive com uma de suas irmãs. Outras duas de suas irmãs ainda estão sob a guarda da BEA. Jeferson agora começa a lutar na justiça para ganhar a guarda de suas irmãs e juntar sua família.

"Tia Rosa, um dia vou buscar minha mãe! Onde ela está? 'Não sei, Jeferson! A última notícia que tive dela, é que voltou para o Mato Grosso! Quer ir atrás dela? '

Meu sonho, tia Rosa, é ajudar minha mãe. Ainda que no papel ela não seja mais a minha mãe, no meu coração ela é. Eu a amo independente do que ela tenha feito, porque ela teve os motivos dela pra agir desta forma. "

E Rosa, com lágrimas nos olhos, sabe com toda a certeza em sua alma: se fosse só por Jeferson, tudo já teria valido a pena!

E nasce no coração de Rosa a esperança de um dia poder voltar a dirigir a BEA. Entretanto uma dúvida paira sobre a sua cabeça: será isso possível? Ou seria melhor ela seguir um novo caminho? Mas qual seria esse novo caminho? Um dilema, Rosa terá de resolver. 